\title{
THE EFFECT OF A SUCCESSION OF OCEAN VENTILATION CHANGES ON ${ }^{14} \mathrm{C}$
}

\section{THOMAS F. STOCKER}

Climate and Environmental Physics, Physics Institute, University of Bern, Sidlerstrasse 5

CH-3012 Bern, Switzerland

and

\section{DANIEL G. WRIGHT}

Fisheries and Oceans Canada, Bedford Institute of Oceanography, P.O. Box 1006, Dartmouth Nova Scotia, Canada B2Y 4A2

\begin{abstract}
Using the model of Stocker and Wright (1996), we investigate the effect of a succession of ocean ventilation changes on the atmospheric concentration of radiocarbon, $\Delta^{14} \mathrm{C}^{\text {atm }}$, the surface reservoir ages, the top-to-bottom age differences, and the calendar ${ }^{14} \mathrm{C}$ age relationships in different regions of the ocean. The model includes a representation of the cycling of ${ }^{14} \mathrm{C}$ through the atmosphere, the ocean and the land biosphere. Ocean ventilation changes are triggered by increasing rates of freshwater discharge into the North Atlantic, which are determined according to a simple feedback mechanism between the melting rates and the climatic state of the North Atlantic region. The results demonstrate that ventilation changes can cause $\Delta^{14} \mathrm{C}^{\mathrm{atm}}$ fluctuations of $25 \%$, surface reservoir age fluctuations of $100 \mathrm{yr}$ in the Pacific (200 yr in the Atlantic) and top-to-bottom age variations of $500 \mathrm{yr}$ in the Pacific (1000 yr in the Atlantic). We also show that ${ }^{14} \mathrm{C}$ age estimates based on marine organisms that live in the near-surface region of the ocean and take up the signal of surface ${ }^{14} \mathrm{C}$ can result in apparent age reversals if the assumption of a constant reservoir age is made.
\end{abstract}

\section{INTRODUCTION}

High-resolution radiocarbon dating has been recognized as an important tool in the investigation of climatic change. Its primary use is in the estimation of chronologies for past events, but ${ }^{14} \mathrm{C}$ dates also contain information on changes in the production rate of atmospheric ${ }^{14} \mathrm{C}$, the globally integrated ventilation rate of the ocean, atmosphere-ocean exchange rates and land biomass. ${ }^{14} \mathrm{C}$ chronologies (Becker, Kromer and Trimborn 1991; Björck et al. 1996; Hughen et al. 1998) are particularly suitable for the reconstruction of such changes as they allow us to construct time series of $\Delta^{14} \mathrm{C}^{\mathrm{atm}}$ in the relevant reservoir. Climate reconstructions based on dynamic models that include ${ }^{14} \mathrm{C}$ as a tracer can use this information to provide a quantitative test of the validity of these reconstructions and the assumptions on which they are based (e.g., reservoir ages). In addition, such models can provide estimates of anomalous variations in ${ }^{14} \mathrm{C}$ age associated with climatic variations.

The purpose of this paper is to estimate the effect of a succession of ocean ventilation changes on $\Delta \Delta^{14} C^{a t m}$, and to show how quantities that are derived from high-resolution ${ }^{14} \mathrm{C}$ dating can be affected by such events. The quantities considered are surface reservoir ages, almost always assumed constant in paleoceanographic reconstructions, top-to-bottom age differences and chronologies. It should be noted that our discussion pertains primarily to marine or lacustrine paleoclimatic archives that are subject to a reservoir age effect. This problem does not arise in tree rings, since in this case $\Delta^{14} \mathrm{C}^{\text {atm }}$ can be accurately reconstructed by taking into account changes of $\delta^{13} \mathrm{C}$.

High-resolution ${ }^{14} \mathrm{C}$ records contain numerous phases of faster and slower advance of the ${ }^{14} \mathrm{C}$ "clock" indicating increasing and decreasing atmospheric concentrations of ${ }^{14} \mathrm{C}$. Part of these fluctuations can be associated with cyclic changes in the production rate of ${ }^{14} \mathrm{C}$ due to changes in the Earth's magnetic field or cosmic radiation (Damon, Lerman and Long 1978; Stuiver and Braziunas 1993). However, some of these variations are particularly rapid or occur in association with contemporaneous climatic changes recorded in these same archives, suggesting that additional processes 
influence the ${ }^{14} \mathrm{C}$ variations. Recently documented examples include the changes of tree ring width in the German chronology (Björck et al. 1996) and a phase of slower increase of the ${ }^{14} \mathrm{C}$ "clock" at the end of Younger Dryas (YD), and changes of the color scale and a contemporaneous strong speedup of the ${ }^{14} \mathrm{C}$ "clock" during the beginning of Younger Dryas as found in the varved marine sediments of Cariaco Basin (Hughen et al. 1998). Such results suggest a climatic origin for some part of these $\Delta^{14} C^{\text {atm }}$ fluctuations.

Stocker and Wright (1996) and Mikolajewicz (1998) have investigated the effect of a collapse of the Atlantic thermohaline circulation on $\Delta^{14} \mathrm{C}^{\text {atm }}$ and found fluctuations of up to $30 \%$ and, if extended changes in the sea ice cover occur, up to $60 \%$. When the circulation is strongly reduced or shut down, $\Delta^{14} C^{a t m}$ increases because the ${ }^{14} \mathrm{C}$ that is continually produced in the atmosphere is less efficiently taken up by the ocean, and hence a greater fraction of it remains in the atmospheric and biospheric reservoirs. When the circulation resumes, the deep ocean, that is by now depleted in ${ }^{14} \mathrm{C}$, is ventilated again and efficiently takes up the excess ${ }^{14} \mathrm{C}$ from the atmosphere. This leads to a period of reduced ${ }^{14} \mathrm{C}$ age variation in both the atmosphere and the upper ocean (a so-called age plateau). Fluctuations of $\Delta^{14} \mathrm{C}^{\mathrm{atm}}$ as reconstructed by Hughen et al. (1998) during the beginning of YD and by Björck et al. (1996) at the end of YD are consistent with rapid turning off and on of the thermohaline circulation. The situation, however, appears to be more complicated during the intervening years. Hughen et al. (1998) found that $\Delta^{14} C^{\text {atm }}$ began to decrease soon after the onset of YD. This suggests that a new ventilation source must have become active during YD; possibilities are intermediate water formation at mid-latitudes in the North Atlantic or the Southern Ocean. Detailed simulations of the YD event that reflect such changes have not yet been achieved by dynamic models. Apart from model shortcomings, we urgently need to know where, when and how much meltwater was discharged into the ocean during deglaciation (Clark et al. 1996).

\section{METHODS}

We use a zonally averaged ocean-atmosphere climate model including a simple representation of the land biosphere. The ocean component includes a representation of the dynamics (Wright, Vreugdenhil and Hughes 1995) of the thermohaline circulation in three basins (Pacific, Atlantic, Indian) interconnected by a circumpolar Southern Ocean. The atmosphere is represented by a linear energy balance formulation (Stocker, Wright and Mysak 1992) and the biosphere is described by a simple fourbox model (Siegenthaler and Oeschger 1987). ${ }^{14} \mathrm{C}$ is included as a tracer that is produced in the atmosphere and exchanged between all three reservoirs. The production rate is determined from the steady-state conditions at the end of a run in which atmospheric ${ }^{14} \mathrm{C}$ is held fixed at $\Delta^{14} \mathrm{C}^{\text {atm }}=0 \%$. Subsequently, the rate of production is held constant so that the changes in ${ }^{14} \mathrm{C}$ considered here are entirely due to changes of the ventilation rate of the ocean. Stocker and Wright (1996) describe the model in detail, and the parameter values used here are identical to those used in our earlier study.

In our previous experiments we treated the freshwater flux perturbation as an externally specified forcing: feedback mechanisms, e.g., between the Northern Hemisphere temperatures and melting rates, were ignored. Here we consider a crude feedback mechanism defined as follows:

$$
F(t)= \begin{cases}R \cdot\left(t-t_{0}\right), & \text { if } F_{H}\left(32^{\circ} \mathrm{N}\right) \geq 0.1 \mathrm{PW}, \\ 0, & \text { otherwise }\end{cases}
$$

where $F(t)$ is the perturbation freshwater flux that we assume to be discharged at $50^{\circ} \mathrm{N}$ in the Atlantic basin. When the meridional heat flux in the Atlantic, $F_{H}$, is small or absent (collapsed circulation) there is no melting, i.e., $F(t)=0$. When the Atlantic heat flux at $32^{\circ} \mathrm{N}, F_{H}\left(32^{\circ} \mathrm{N}\right)$, first exceeds 0.1 
PW $\left(1 \mathrm{PW}=10^{15} \mathrm{~W}\right)$ at $t=t_{0}$, melting begins and increases at the constant rate $R$ (in $\left.\mathrm{m}^{3} \mathrm{~s}^{-2}\right)$ as long as the heat flux remains above $0.1 \mathrm{PW}$. This represents the simplest possible feedback mechanism between a climatic variable simulated by the model and the freshwater perturbation. Although we cannot give a quantitative justification for this choice, we note that a binge-purge mechanism was proposed for partly disintegrating ice sheets (MacAyeal 1993a,b) with the effect that ice discharge rates increase progressively with time. For the present experiments we select $R=2.4 \cdot 10^{-6} \mathrm{~m}^{3} \mathrm{~s}^{-2}=$ $0.075 \mathrm{~Sv} \mathrm{ka}^{-1}\left(1 \mathrm{~Sv}=10^{-6} \mathrm{~m}^{3} \mathrm{~s}^{-1}\right)$. Note that the continually increasing rate of input of freshwater will eventually cause the Atlantic overturning circulation to collapse. At this time, the supply of heat to the high northern latitudes will be strongly reduced, and melting will be stopped.

It is not immediately clear what the long-term effect of this feedback mechanism on the deep circulation will be; there are several possibilities that might be consistent with the model dynamics. First, a quasi-steady state could develop in which the freshwater perturbation keeps the overturning circulation fluctuating around small values with meridional heat fluxes on the order of $0.1 \mathrm{PW}$. A second possibility is that the circulation might break down completely and a new steady state establish with little or no Atlantic overturning. In this scenario, the heat flux would never again exceed the critical value of $0.1 \mathrm{PW}$ and there would be no further melting. The third possibility is that the circulation might collapse but recover. As the circulation recovers and the heat flux exceeds $0.1 \mathrm{PW}$, the meltwater input might have little effect until it grows to a critical value at which the circulation collapses again, and the cycle repeats.

The third possibility discussed above depends critically on the recovery phase, which might, for example, result from the significant cooling of high northern latitudes that would accompany the collapse of the overturning circulation, or it might be induced by increased high-latitude surface salinity after the meltwater input is terminated. In this regard, it should be noted that recovery is encouraged by the fact that the meltwater input is terminated as soon as the circulation collapses. This is a significant difference from previous experiments in which the meltwater input was specified independently of the model's climatic state.

\section{Model Response}

Figure 1 illustrates a typical model response, which is clearly of the third type. Meltwater input is initiated at $t=1000 \mathrm{ka}$ and increases linearly at the specified rate of $0.075 \mathrm{~Sv} \mathrm{ka}^{-1}$. After ca. $2 \mathrm{ka}$ the Atlantic circulation decreases abruptly (Fig. 1a), then recovers temporarily and completes its collapse by the time the meltwater input reaches $c a$. $0.26 \mathrm{~Sv}$. At this point, the meltwater input is reduced to zero, and soon afterwards the circulation recovers rapidly to maximum strength. Subsequently, the cycle is repeated almost identically. Thus, the model responds with a succession of gradual coolings and abrupt warmings that are strongest in the Northern Hemisphere. The time scale of the oscillation is determined by $R$, but the qualitative nature of the variability is not sensitive to the value of $R$.

The model atmospheric temperature at $72^{\circ} \mathrm{N}$ gradually decreases as the meltwater input increases until the circulation collapses, at which point the temperature decreases abruptly, increases again as the circulation recovers and then decreases to near zero as the circulation completes its collapse (Fig. 1b). Once the Atlantic thermohaline circulation shuts down and the meridional heat flux drops below $0.1 \mathrm{PW}$, the meltwater input stops. A few hundred years later, the circulation resumes again, resulting in an abrupt warming. It is remarkable that time scales of cooling and warming much like those seen in Figure 1b are found to be a common feature of the Dansgaard/Oeschger cycles found in marine sediments (Bond et al. 1993) and Greenland ice cores (GRIP 1993). In particular, our 

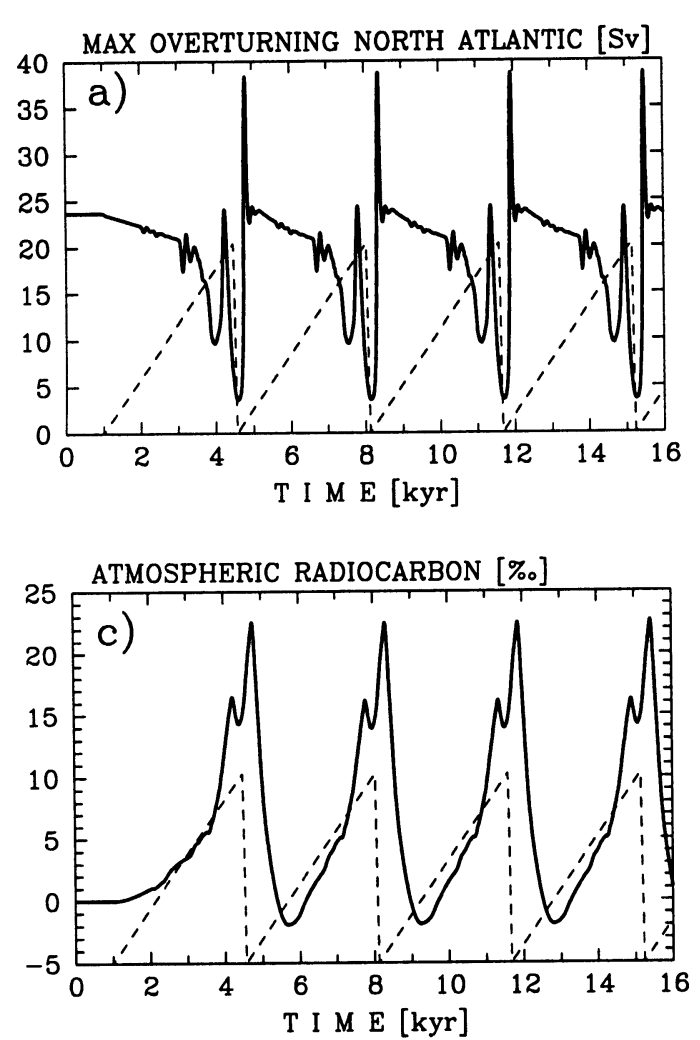

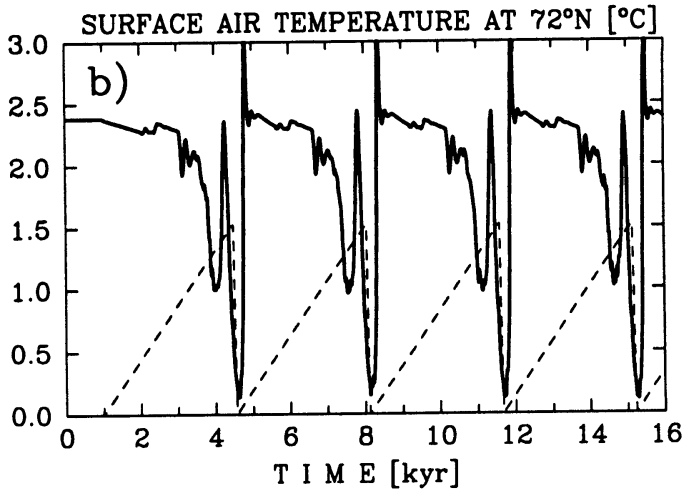

Fig. 1. (a) Evolution of the maximum overturning in the North Atlantic as a result of the meltwater flux perturbations $(--)$. When the meltwater flux increases at a rate of $0.075 \mathrm{~Sv}$ $\mathrm{ka}^{-1}$, the weakening of the thermohaline circulation occurs on the same time scale and is gradual, but punctuated by some shorter cold events. The maximum meltwater discharge is $0.26 \mathrm{~Sv}$. A few hundred years after the meltwater discharge is stopped, the thermohaline circulation switches on abruptly. (b) Evolution of surface air temperature at $72^{\circ} \mathrm{N}$ as a result of changing meridional heat flux associated with the thermohaline circulation. (c) Evolution of $\Delta^{14} C^{\text {atm }}$, the atmospheric concentration of ${ }^{14} \mathrm{C}$. During the coolings $\Delta^{14} \mathrm{C}^{\mathrm{atm}}$ increases by $c a$. $25 \%$ and then decreases quickly during the abrupt warmings. The latter decrease leads to age plateaus.

model results suggest that warming events follow times of maximum discharge with a lag, a scenario not unlike that indicated by the paleoclimatic record of Heinrich events.

The abrupt changes in ocean circulation are reflected in associated changes in the content of atmospheric ${ }^{14} \mathrm{C}$ (Fig. 1c); the signal is low-pass filtered with respect to high-latitude temperature (Fig. 1b) due to the damping effects of exchanges of ${ }^{14} \mathrm{C}$ between the surface reservoir and both the atmosphere and the deep ocean. $\Delta^{14} \mathrm{C}^{\mathrm{atm}}$ increases during the time of gradual cooling in the North Atlantic and continues to increase after the collapse until the circulation recovers. The maximum increase of $\Delta^{14} C^{\text {atm }}$ is $c a .25 \%$. The abrupt warming is due to the reinitiation of the overturning circulation, which also initiates a rapid decrease of $\Delta^{14} C^{\text {atm }}$ and leads to a period of reduced speed of the ${ }^{14} \mathrm{C}$ "clock" (a plateau).

\section{RESULTS}

We now discuss quantities related to ${ }^{14} \mathrm{C}$ that can be measured in marine paleoclimatic archives. We select three "coring sites" in the model: $39^{\circ} \mathrm{N}$ in both Pacific and Atlantic and $60^{\circ} \mathrm{N}$ in the latter. The maximum depth across each of these sections is $4000 \mathrm{~m}$, but we assume that the cores are taken at a local water depth of $2250 \mathrm{~m}$, and we consider time series of surface reservoir ages and top-to-bottom age differences that would be recorded at these sites.

Figure 2 shows time series of the surface reservoir age at the three "coring sites". It is evident that these ages do not remain constant but vary by 100-200 yr depending on the location. Reduced deep ventilation results in higher ${ }^{14} \mathrm{C}$ content of the atmosphere. This signal is rapidly transmitted to the 

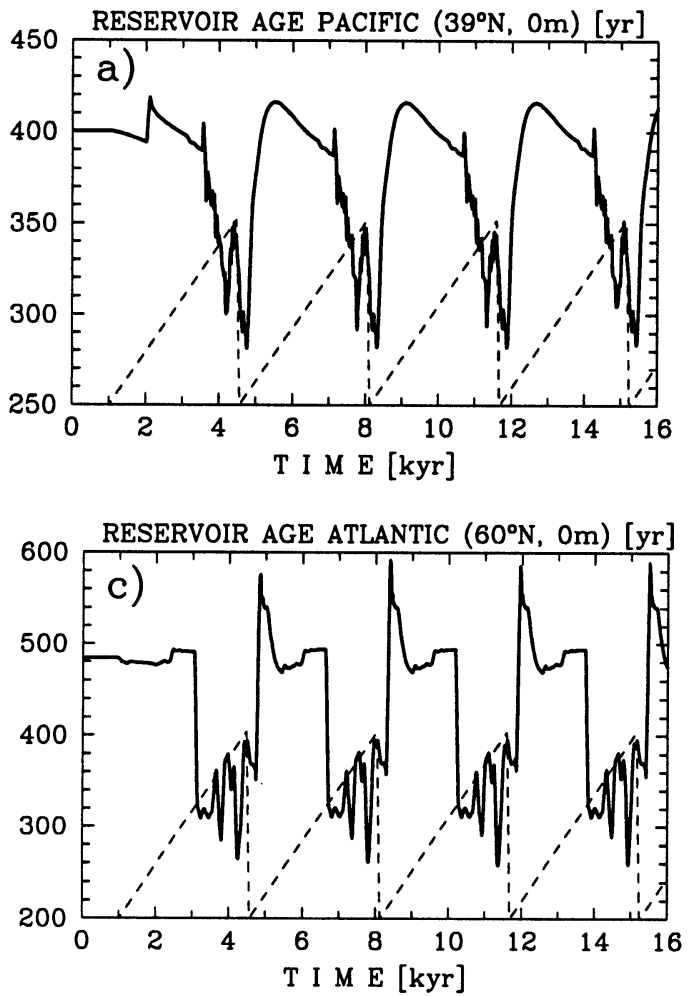

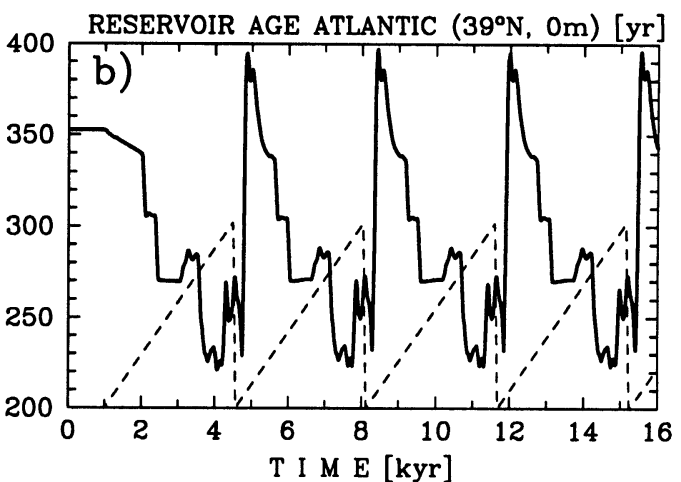

Fig. 2. Evolution of the surface reservoir age in the $\mathrm{Pa}$ cific at $39^{\circ} \mathrm{N}$ (a) and the Atlantic at $39^{\circ} \mathrm{N}$ (b), and $60^{\circ} \mathrm{N}$ (c). The age decreases during the cooling because of the reduced ventilation of the deep ocean. At the time of abrupt warming, deep waters that are depleted in ${ }^{14} \mathrm{C}$ are rapidly mixed to the surface, increasing the surface reservoir age in the Pacific and mid-latitude Atlantic. There is a slight increase of the surface reservoir age in the Atlantic at $60^{\circ} \mathrm{N}$ during the cooling period. Remote regions may also be influenced by local convection changes, but the changes in the North Atlantic are rapidly communicated to all regions through the atmosphere. Note the scales for the reservoir ages at different locations.

surface waters, lowering the apparent age and consequently speeding up the ${ }^{14} \mathrm{C}$ "clock" during the adjustment period (Fig. 2a, b). Reinitiation of the ventilation increases the surface reservoir ages again. The increase is very rapid in the Atlantic, where the strongest circulation changes occur. At high latitudes in the Atlantic, this increase occurs already during the cold phase because of the large changes in the vertical mixing (Fig. 2c). This is consistent with the findings of Bard et al. (1994) who report an increase of the surface reservoir age during the cooling phase of YD. However, the increase is much smaller than in earlier experiments (Stocker and Wright 1996: Fig. 13) because here the maximum increase of $\Delta^{14} C^{\text {atm }}$ is smaller (cf. standard experiment $C 2$ of Stocker and Wright (1996)).

Although the Pacific experiences only small circulation changes, Figure $2 \mathrm{a}$ shows that the ${ }^{14} \mathrm{C}$ signal is still substantial there. This is primarily due to the fact that the changes in atmospheric ${ }^{14} \mathrm{C}$ associated with the reduced ventilation are efficiently transmitted to the ocean surface reservoir all around the globe. This again suggests that YD-type signals, which originate in the North Atlantic, are also to be expected in remote areas, since they can be efficiently transmitted through the atmosphere (Stocker and Wright 1996; Mikolajewicz et al. 1997).

The temporal evolution of top-to-bottom age differences is presented in Figure 3. In the Pacific, the age difference increases by ca. $400 \mathrm{yr}$ during the cooling. $\mathrm{Ca}$. $100 \mathrm{yr}$ can be explained by a decrease of the surface reservoir age; the rest is due to the cessation of the inflow of younger Atlantic water into the deep Pacific. The two Atlantic sites exhibit more dramatic variations: age differences increase by $c a$. $1000 \mathrm{yr}$, most of which is due to the aging of the deep Atlantic associated with the reduced exchange with the surface reservoir when the Atlantic overturning circulation is sluggish (Fig. 3b, c). It must be noted, however, that this increase during the cooling period, and the subse- 

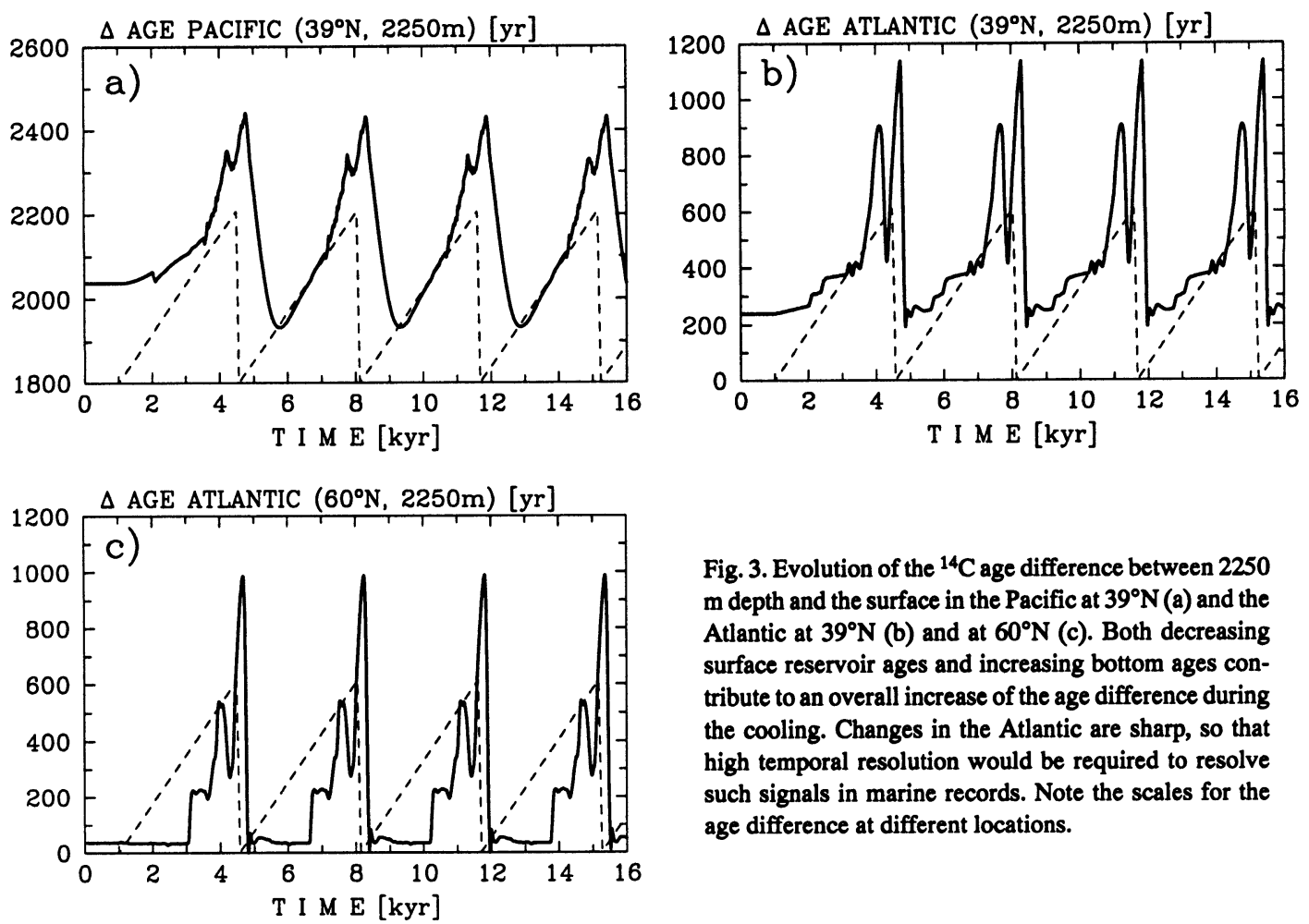

Fig. 3. Evolution of the ${ }^{14} \mathrm{C}$ age difference between 2250 $m$ depth and the surface in the Pacific at $39^{\circ} \mathrm{N}$ (a) and the Atlantic at $39^{\circ} \mathrm{N}\left(\right.$ b) and at $60^{\circ} \mathrm{N}$ (c). Both decreasing surface reservoir ages and increasing bottom ages contribute to an overall increase of the age difference during the cooling. Changes in the Atlantic are sharp, so that high temporal resolution would be required to resolve such signals in marine records. Note the scales for the age difference at different locations.

quent rapid decrease following the warming, happen within a relatively short time interval. Therefore, high-resolution ${ }^{14} \mathrm{C}$ dating (resolution of a century or better) will be required in order to resolve this signal. Changes in regions away from the North Atlantic occur on somewhat slower time scales but are significantly reduced in magnitude (Fig. 3a).

Finally, we address the possibility of apparent age reversals. These can occur when the surface reservoir ages increase rapidly at the time of commencement of the circulation. This period is associated with increasing levels of convection that mix up deep waters depleted in ${ }^{14} \mathrm{C}$. In order to quantify the maximum possible effects, we base our considerations on the phase of rapid commencement of the circulation in experiment I5 of Stocker and Wright (1996: Fig 12d). This experiment shows the largest transient changes in $\Delta^{14} \mathrm{C}^{\mathrm{atm}}$ (up to $+58 \%$ ), because of enhanced sea ice cover, and hence reduced air-sea exchange, during the time of collapsed circulation.

Figure 4 shows three chronologies of ${ }^{14} \mathrm{C}$ age $v s$. real time, including a climate indicator (North Atlantic sea surface temperature at $60^{\circ} \mathrm{N}$ ). The atmospheric chronology is most often discussed because of the absolute time scales provided by tree rings and varved lake and marine sediments. The model's atmospheric chronology is shown in Figure 4a. A plateau of $c a .290 \mathrm{yr}$ is visible that straddles the time of rapid climatic warming. If we construct a chronology based on ${ }^{14} \mathrm{C}$ dates of a marine near-surface core in the Pacific, and assume a constant reservoir age of $670 \mathrm{yr}$, we obtain a result similar to the atmospheric chronology. This is as expected from the previous discussion of the atmospheric influence on the ${ }^{14} \mathrm{C}$ content of the surface reservoir in the Pacific. However, assuming a constant reservoir age of $430 \mathrm{yr}$ for a marine near-surface core in the Atlantic results in an apparent age reversal. This age reversal is a direct consequence of the exchange with the ${ }^{14} \mathrm{C}$-depleted deep reservoir when convection and the overturning circulation are reinitiated in the North Atlantic. 

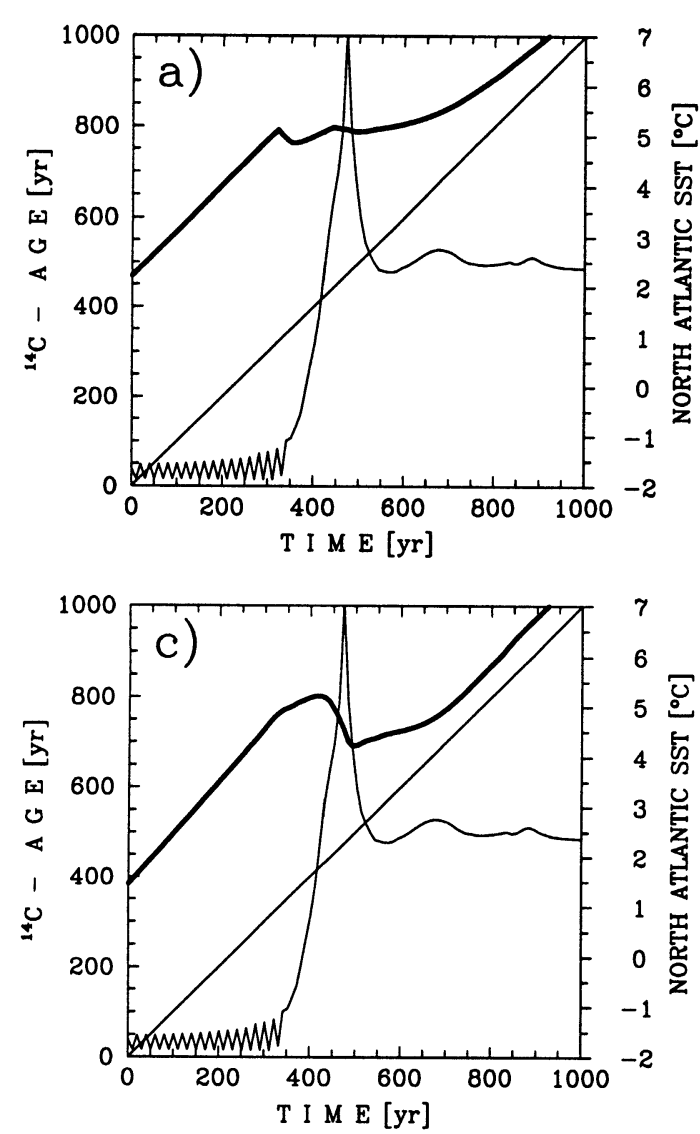

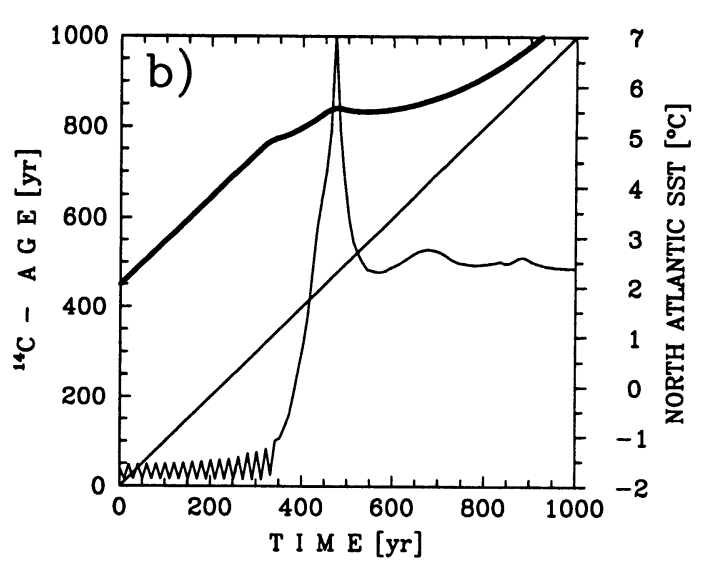

Fig. $4 .{ }^{14} \mathrm{C}$ chronology (thick solid line) during an event of abrupt warming. The atmospheric chronology (a) is based on the evolution of $\Delta^{14} C^{\text {atm }}$. Chronologies can also be constructed from marine records from the surface $\mathrm{Pa}$ cific (b) and the surface Atlantic (c). The usual assumption of constant reservoir ages $(670 \mathrm{yr}$ and $430 \mathrm{yr}$ for the Pacific and Atlantic, respectively) leads to apparent age reversals at locations where the ventilation changes significantly (Atlantic, (c)). A change in the values of the constant reservoir ages simply leads to a vertical shift of the curves. The straight thin solid line indicates the undisturbed chronology (no changes of $\Delta^{14} C^{\text {atm }}$ ); the thin solid curve is the sea surface temperature in the Atlantic during the termination of the cold event.

However, the signal is muted by exchange with the atmosphere, so that the maximum time offset does not exceed ca. $325 \mathrm{yr}$, and the time interval of the age reversal lasts for less than $150 \mathrm{yr}$.

\section{Conclusion}

Using a dynamic ocean-atmosphere model, including a simple land biosphere and a representation of the cycling of ${ }^{14} \mathrm{C}$, we have investigated the effect of a succession of gradual Atlantic circulation collapses (coolings) and abrupt recoveries (warmings) on the ${ }^{14} \mathrm{C}$ concentration of the atmosphere and related quantities in the ocean. Such climatic fluctuations are characteristic of the last glacial: their signatures in ice and sediment cores are commonly referred to as Dansgaard/Oeschger and Heinrich events.

In the experiments considered here, we found that $\Delta^{14} \mathrm{C}^{\mathrm{atm}}$ changes by $\mathrm{ca} .25 \%$. If larger parts of the sea surface become ice-covered this value may increase to ca. 60\%o (Stocker and Wright 1996). The corresponding changes seen in the ocean surface reservoir ages exhibit substantial spatial variation. Reservoir ages increase by $c a .200 \mathrm{yr}$ in the North Atlantic immediately following the abrupt warming; the response in the Pacific is slightly delayed and less pronounced. Top-to-bottom age differences document the changes in the distribution of ${ }^{14} \mathrm{C}$ most clearly. During the cooling they may increase by about $1 \mathrm{ka}$ in the Atlantic ( $400 \mathrm{yr}$ in the Pacific), only to decrease again at the time of the abrupt warming. Changes are particularly fast in the Atlantic, so that their detection in marine records would require high temporal resolution. Predicted changes in the Pacific are somewhat less 
abrupt and reduced in amplitude. Finally, we showed that if age estimates are determined under the assumption that surface reservoir ages are constant, then apparent age reversals may occur in the marine records coincident with age plateaus in the atmospheric records. These age reversals are removed if the correct evolution of the surface reservoir age is taken into account.

\section{ACKNOWLEDGMENTS}

This study was supported by the Swiss National Science Foundation and the Natural Sciences and Engineering Research Council of Canada through the Climate System History and Dynamics Project. We are grateful to $O$. Marchal and an anonymous reviewer for useful comments.

\section{REFERENCES}

Bard, E., Arnold, M., Mangerud, J., Paterne, M., Labeyrie, L., Duprat, J., Mélières, M.-A., Sønstegaard, E. and Duplessy, J.-C. 1994 The North Atlantic atmosphere-sea surface ${ }^{14} \mathrm{C}$ gradient during the Younger Dryas climatic event. Earth and Planetary Science Letters 126: 275-287.

Becker, B., Kromer, B. and Trimborn, P. 1991 A stableisotope tree-ring timescale of the Late Glacial/Holocene boundary. Nature 353: 647-649.

Björck, S., Kromer, B., Johnsen, S., Bennike, O., Hammarlund, D., Lemdahl, G., Possnert, G., Rasmussen, T. L., Wohlfarth, B., Hammer, C. U. and Spurk, M. 1996 Synchronised terrestrial-atmospheric deglacial records around the North Atlantic. Science 274: 11551160.

Bond, G., Broecker, W. S., Johnsen, S. J., McManus, J., Labeyrie, L., Jouzel, J. and Bonani, G. 1993 Correlations between climate records from North Atlantic sediments and Greenland ice. Nature 365: 143-147.

Clark, P. U., Alley, R. B., Keigwin, L. D., Licciardi, J. M., Johnsen, S. J. and Wang, H. 1996 Origin of the first global meltwater pulse. Paleoceanography 11: 563577.

Damon, P. E., Lerman, J. C. and Long, A. 1978 Temporal fluctuations of atmospheric ${ }^{14} \mathrm{C}$ : Causal factors and implications. Annual Review of Earth and Planetary Sciences 6: 457-494.

GRIP members 1993 Climate instability during the last interglacial period recorded in the GRIP ice core. $\mathrm{Na}$ ture 364: 203-207.

Hughen, K. A., Overpeck, J. T., Lehman, S. J., Kashgarian, M., Southon, J., Peterson, L. C., Alley, R. and Sigman, D. M. 1998 Deglacial changes in ocean circula- tion from an extended radiocarbon calibration. Nature 391: 65-68.

MacAyeal, D. R. 1993a Binge/purge oscillations of the Laurentide ice sheet as a cause of the North Atlantic's Heinrich event. Paleoceanography 8: 775-784.

1993b A low-order model of the Heinrich event cycle. Paleoceanography 8: 767-773.

Mikolajewicz, U. 1998 A meltwater-induced collapse of the "conveyor belt" thermohaline circulation and its influence on the distribution of $\Delta^{14} \mathrm{C}$ and $\delta^{18} \mathrm{O}$ in the oceans. Journal of Geophysical Research, in press.

Mikolajewicz, U., Crowley, T. J., Schiller, A. and Voss, R. 1997 Modelling teleconnections between the North Atlantic and North Pacific during the Younger Dryas. Nature 387: 384-387.

Siegenthaler, U. and Oeschger, $\mathrm{H} .1987$ Biospheric $\mathrm{CO}_{2}$ emissions during the past 200 years reconstructed by convolution of ice core data. Tellus 39B: 140-154.

Stocker, T. F. and Wright, D. G. 1996 Rapid changes in ocean circulation and atmospheric radiocarbon. Paleoceanography 11: 773-796.

Stocker, T. F., Wright, D. G. and Mysak, L. A. 1992 A zonally averaged, coupled ocean-atmosphere model for paleoclimate studies. Journal of Climate 5: 773797.

Stuiver, M. and Braziunas, T. F. 1993 Modeling atmospheric ${ }^{14} \mathrm{C}$ influences and ${ }^{14} \mathrm{C}$ ages of marine samples to 10,000 BC. In Stuiver, M., Long, A. and Kra, R. S., eds., Calibration 1993. Radiocarbon 35(1): 137-189.

Wright, D. G., Vreugdenhil, C. B. and Hughes, T. M. 1995 Vorticity dynamics and zonally averaged ocean circulation models, Journal of Physical Oceanography 25: 2141-2154. 